\title{
Case report of a sebaceous carcinoma of the eyelid
}

\section{Afellah Mohammed, Fadel Reda, Kamal Dounia, Elalami Elamine Mohamed Noureddine}

\author{
Service de Chirurgie Maxillofaciale, ORL, et CCF, Hôpital Omar Idrissi, CHU Hassan II Fez, Morroco
}

Corresponding author: Afellah Mohammed, MD, E-mail: mohamed.afellah@gmail.com

\begin{abstract}
Sebaceous carcinoma of the eyelid is a relatively rare entity. A 70 year old woman presented with a left lower eyelid swelling growing over the last year. Upon examination, the external two thirds of the tarsal edge were swollen, inflamed, and bleeding on palpation. The pathological examination was in favor of a sebaceous carcinoma. The patient underwent a surgical excision and the outcome was satisfactory. The palpebral sebaceous carcinoma is variable and can mimic various benign conditions, explaining the frequent diagnostic delays. The treatment is surgical. It consists of a complete resection of the lesion associated with wide safety margins. Only an early diagnosis associated with a large surgical excision improves the prognosis.
\end{abstract}

Key words: Sebaceous carcinoma; Eyelid; Excision

\section{INTRODUCTION}

Sebaceous carcinoma of the eyelid is a relatively rare entity. Tumoral proliferation of the eyelid's sebaceous glands, it mimics several clinical presentations. We report the case of a patient with an inferior palpebral sebaceous carcinoma who underwent successful surgical excision.

\section{CASE REPORT}

A 70 year old woman, with no medical history, presented to the outpatient clinic with a chief complaint of a left lower eyelid swelling growing over the last year (Fig. 1).

Upon examination, the external two thirds of the tarsal edge were swollen, inflamed, and bleeding on palpation. No clinical extension to the orbit, nor cervical lymph nodes, were noted. We performed a biopsy, and a CT scan. The pathological examination was in favor of a sebaceous carcinoma, and the CT scan showed a 4 millimeters enlargement of the left lower eyelid with no orbital extension. The patient underwent a surgical excision of the carcinoma with 5 millimeters margins (Fig. 2).
The final histological examination confirmed the diagnosis and the microscopic margins were satisfactory. A palatine mucosa graft associated with a cheek advancement flap was used to repair the defect. A three month follow up showed a well healed eyelid with minimal lagophthalmos and no sign of recurrence (Fig. 3).

\section{DISCUSSION}

The palpebral sebaceous carcinoma is variable and can mimic various benign conditions, explaining the frequent diagnostic delays. Thus, a period of 6 months is often necessary between the first clinical signs and obtaining a definite diagnosis. This lesion can extend to the eyelids but also to the conjunctiva, the eyeball and can even metastasize to regional lymph nodes or distant organs. The average age at diagnosis is around 70 years. In Western countries, Caucasian women are the most affected (standard deviation 39 to 90 years) $[2,3]$. The delay diagnosis is 1 month to 4 years, with an average of about 15 months. The upper eyelids are more frequently affected than the lower ones due to a greater number of sebaceous glands. Clinical signs are often considered mild at the early

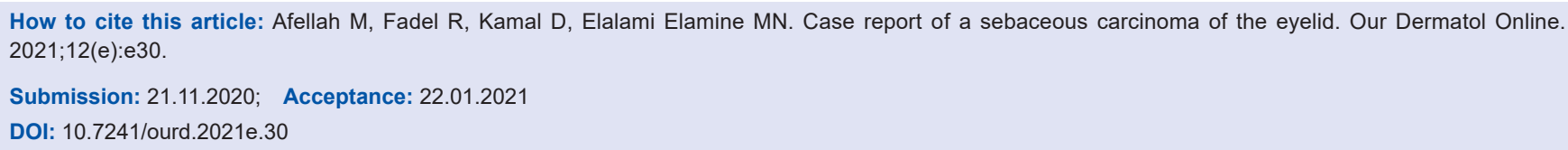




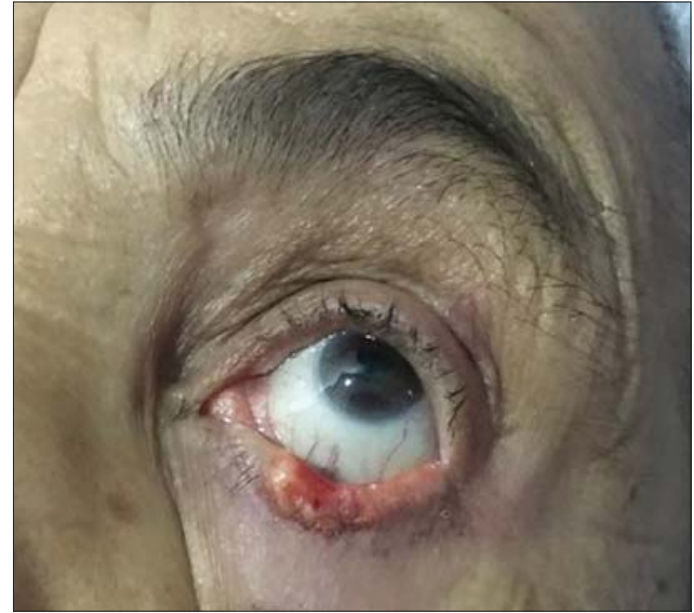

Figure 1: Preoperative presentation of the sebaceous carcinoma.

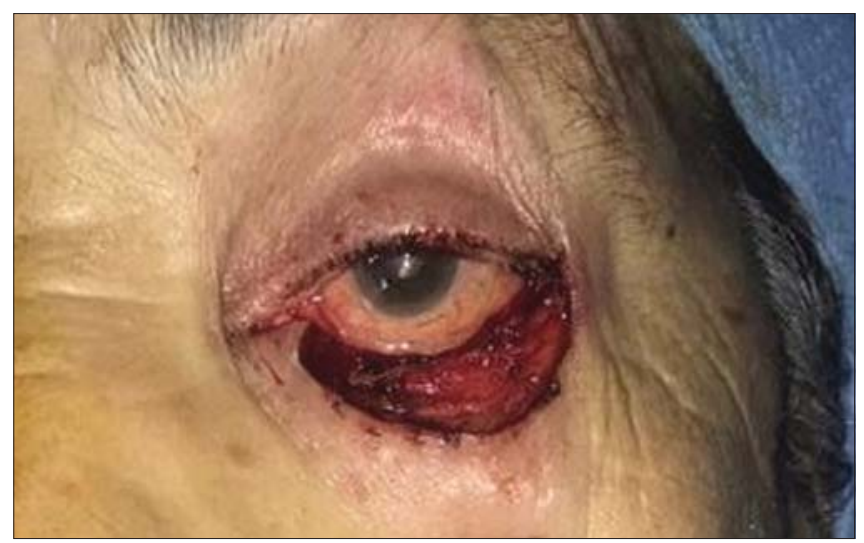

Figure 2: Intraoperative aspect after tumor excision.

stage of disease. Redness is often found associated with eyelid swelling. This change in volume can either take on the appearance of a nodule or from diffuse infiltration of the entire eyelid. The diagnosis most often mentioned at the initial stage is that of chalazion or meibomian cyst. At more advanced stages, when the lesion resists local treatments or surgical drainage, the diagnosis most often mentioned is that of squamous cell carcinoma, basal cell carcinoma or even lymphoma. The treatment is surgical. It consists of a complete resection of the lesion associated with wide safety margins (more than $4 \mathrm{~mm}$ ). Intersections with extemporaneous histopathological examination seem essential. Only a wide resection with, if necessary, reconstruction on an unevolved (non-metastatic) tumor allows healing [1,4-7].

\section{CONCLUSION}

The sebaceous carcinoma must always be on the mind of the practitioner. A thorough examination and an

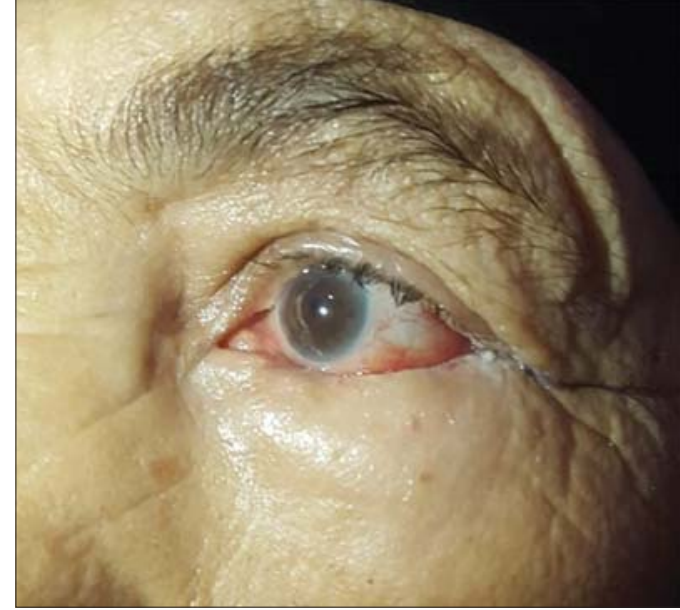

Figure 3: Healed appearance three months after surgery.

early biopsy, associated with a large surgical excision highly improve the prognosis.

\section{Consent}

The examination of the patient was conducted according to the principles of the Declaration of Helsinki.

The authors certify that they have obtained all appropriate patient consent forms, in which the patients gave their consent for images and other clinical information to be included in the journal. The patients understand that their names and initials will not be published and due effort will be made to conceal their identity, but that anonymity cannot be guaranteed.

\section{REFERENCES}

1. Ho VH, Ross MI, Prieto VG, Khaleeq A, Kim S, Esmaeli B. Sentinel lymph node biopsy for sebaceous cell carcinoma and melanoma of the ocular adnexa. Arch Otolaryngol Head Neck Surg. 2007;133:820-6.

2. Shields JA, Shields CL, Marr BP, Eagle RC Jr. Sebaceous carcinoma of the caruncle. Cornea. 2006;25:858-9.

3. Lan MC, Lan MY, Lin CZ, Ho DM, Ho CY. Sebaceous carcinoma of the eyelid with neck metastasis. Otolaryngol Head Neck Surg, 2007;136:670-1.

4. Muqit MM, Roberts F, Lee WR, Kemp E. Improved survival rates in sebaceous carcinoma of the eyelid. Eye (lond). 2004;18:49-53.

5. Burns SJ, Foss AJ, Butler TK. Outcome of periocular sebaceous gland carcinoma. Ophthal Plast Reconstr Surg. 2005;21:353-5.

6. Galatoire O. Carcinome sébacé palpébral Eyelid sebaceous carcinoma. Service de chirurgie orbitaire et oculo-plastique, fondation ophtalmologique A. de Rothschild, Paris. Imag Ophtalmol. 2011;5.

7. Prieto-Granada C, Rodriguez-Waitkus P. Sebaceous carcinoma of the eyelid. Cancer Control. 2016;23:126-32.

Copyright by Afellah Mohammed, et al. This is an open access article distributed under the terms of the Creative Commons Attribution License, which permits unrestricted use, distribution, and reproduction in any medium, provided the original author and source are credited.

Source of Support: Nil, Conflict of Interest: None declared. 